\title{
CLINICAL AND RADIOGRAPHICAL EVALUATION OF IMMEDIATE IMPLANT VERSUS DELAYED IMPLANT AFTER SOCKET PRESERVATION OF UPPER ANTERIOR TEETH
}

\author{
El Sayed $\mathrm{E}^{1} B D S$, Khalil $\mathrm{A}^{2} P h D$, Saleh $\mathrm{M}^{2} P h D$.
}

\begin{abstract}
:
Introduction: After tooth extraction, the alveolar bone remodeled and resorbed. The preservation of ridge resorption following tooth extraction through socket grafting helped to optimize bony fill, thereby maintaining vertical bone height and helped to stabilize the marginal soft tissue at the site. Adequate bone allowed the implant to be placed in the most ideal restorable position in a three dimensional aspect which yielded higher longterm success.

Objectives: Clinical and radiographical evaluation of immediate post extraction implants versus delayed implants after socket preservation. Materials and Methods: 14 patients were selected for this study and divided into two groups, study group consist of 7 patients with extracted upper anterior teeth and the sockets have been preserved with Easy-graft material, the implants were placed after 6 months of healing. In control group implants were placed immediately after extraction of upper anterior teeth with placement of Easy-graft material around them.

Results: Clinical evaluation of all patients showed no signs of gingival inflammation and none of the implants showed any signs of mobility all over the study period. Regarding peri-implant probing depth and marginal bone height, there was no statistically significant difference between the two groups.
\end{abstract}

Conclusions: There was no difference between immediate implant and delayed implant after socket preservation with regards to the marginal bone height and bone density.

Key words: Socket preservation, delayed, immediate, implants.

1- $\quad$ B.D.S., Faculty of Dentistry, Alexandria University

2- Professor of Oral and Maxillofacial Surgery, Faculty of Dentistry, Alexandria University

\section{INTRODUCTION}

After tooth extraction, the alveolar bone remodels and resorbs. Two-thirds of this occurs within the first 3 months and within 1 year the clinical width of the alveolar ridge is reduced by approximately $50 \%$. The mean vertical loss of tissues at single extracted sites ranges between 1 and $4 \mathrm{~mm}$ depending on site location. This localized alveolar bone resorption may affect the possibility of placing dental implants and their aesthetic outcome. Prevention of ridge resorption following tooth extraction seems important, particularly if implant placement needs to be delayed for 6 months or longer. Site preservation through socket grafting will help to optimize bony fill within the extraction socket, thereby maintaining vertical bone height and helping to stabilize the marginal soft tissues at the site. This generally results in a healed site, which lends itself well to implant placement with a high degree of predictability as well as improved soft tissue contour or 'pink' aesthetic (1-3).

A number of different materials have been suggested for use in extraction sockets, however not all are suitable. The decision on what is used should be based on biological principles. A graft material should be biocompatible, support vital bone formation into the socket in order to allow for successful osseointegration of the dental implant that will subsequently be placed into the site. Thus, it is also preferable that the material used is resorbable and ultimately replaced with long term vital bone (4-9).

Easy-graft materials are bioresorbable, completely synthetic bone graft substitutes for bone defects. In contact with body fluids such as blood or saliva the material hardens within minutes and forms a stable, porous bone substitute material. Due to the porosity of the material, the absorption of blood is possible and thus positively influences the healing process (10).

This study aims to compare clinically and radiographically between implants placed immediately after tooth extraction in fresh extraction sockets with implants placed in a preserved socket after 6 months of healing.

\section{MATERIALS AND METHODS}

\section{Patients}

Fourteen patients were selected for this study from the Outpatient Clinic of Oral and Maxillofacial Surgery Department, Faculty of Dentistry Alexandria University.

The Patients were divided into two groups:

Group I (study group): This group consisted of seven patients with extracted upper anterior teeth followed by socket preservation with easy graft material. The implant was placed after 6 months of healing.

Group II (control group): This group consisted of seven patients with upper anterior teeth indicated for extraction. The implant placed immediately after extraction and easy graft was grafted at the coronal third of the socket.

\section{Inclusion criteria}

- Extracted upper anterior tooth with the presence of adjacent dentition.

- Presence of adequate and healthy gingiva of surrounding dentition.

- Good oral hygiene.

- Patient age ranging from 20-50 years old. 


\section{Exclusion criteria}

- Presence of active infection around the tooth.

- Medically compromised patient.

- Dental history of bruxism and parafunctional habits.

- Untreated periodontitis.

- Bone disease that affects bone formation.

- Patient with insufficient inter-occlusal and mesiodistal spaces for implant placement.

- Smokers.

\section{Informed consent}

An informed consent was obtained from the patients. All the procedures were described in detail including the benefits and side effects. It was also mentioned that the patient has the right of withdrawal from the study anytime according to their wish.

\section{Materials}

Implant System: Dentium implant system (Superine, 3105 Trade Tower 159, Samsung-dong, Gangnam-gu, Seoul, Korea).

The implant is available in different diameters ranging from (3.6 $\mathrm{mm}$ to $7.0 \mathrm{~mm}$ ) and lengths ranging from $(7 \mathrm{~mm}$ to 14 $\mathrm{mm}$ ) according to the requirement.

Graft material: Easy-graft TM" classic" (Degradable solution AG, Wagistrasse 23, 8952 Sthlieren, Switzerland). Easy graft classic materials are bioresorbable and are completely synthetic bone graft substitutes for bone defect. The material is supplied in a syringe form, which is filled with roundish, porous granules of pure phase beta tricalcium phosphate each granule is coated with 10 micron of fast resorbing polylactic-co-glcolic acid, and an ampoule of liquid activator, biolinker (organic solvent consisting mostly of n-methyl-2-pyrrolidone) (11). When combining these two components, the easy - graft material becomes a putty- like biomaterial and can be applied directly from the syringe into the bone defect. In contact with body fluids such as blood or saliva the material hardens within minutes and form a stable porous bone substitute material.

\section{Pre-surgical phase}

- Primary alginate impression was taken for both arches and casting diagnostic study models.

- Evaluation of interarch relationship, interocclusal space that could accommodate the implant abutment and the future crown restoration both clinically and on the study model.

- Fabrication of surgical guide stent using the primary model.

- Orthopantomogram (OPG) was done for all patients to detect bone quality and approximation to important anatomical structures.

- Cone beam to detect length and diameter of implant.

\section{Surgical phase}

Group I (study group)

- All patients were operated under local anesthesia secured with Mepevacaine Hydrochloride 2\% with Levonordefrin 1:20000 (Mepecaine L, Alexandria Co. for pharmaceutical \& chemical industries, Alexandria, Egypt) and strict aseptic conditions.

- Crestal incision was made and flap reflected.
- Pilot osteotomy was drilled with surgical stent in place.

- Final osteotomy was drilled with drills of subsequent sizes up to the proper size of the implant. (Figure 1)

- Implant was inserted using hand wrench and then finally seated down to the full depth using ratchet wrench.

- Implant mount was removed and cover screw derived in place. (Figure 2)

- The flap was sutured with interrupted sutures.

Group II (control group)

- All patients were operated under local anesthesia.

- Atraumatic extraction of upper anterior tooth in order to protect and preserve the alveolar bone. (Figure 3)

- Curettage and proper debridement of the socket to remove any inflamed tissues.

- The socket was prepared with drills of subsequent sizes up to the proper size of the implant. Osteotomy was extended 3-4 mm beyond the root apex.

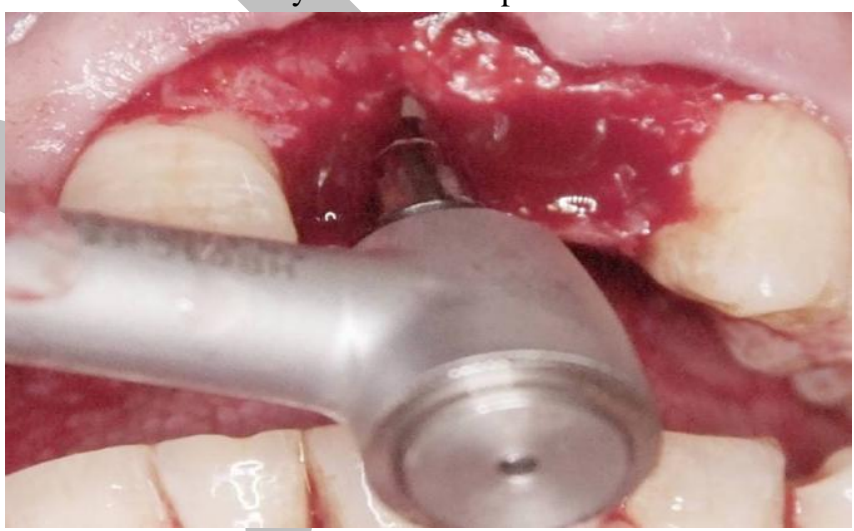

Fig. 1: Showing osteotomy for implant placement (study group)

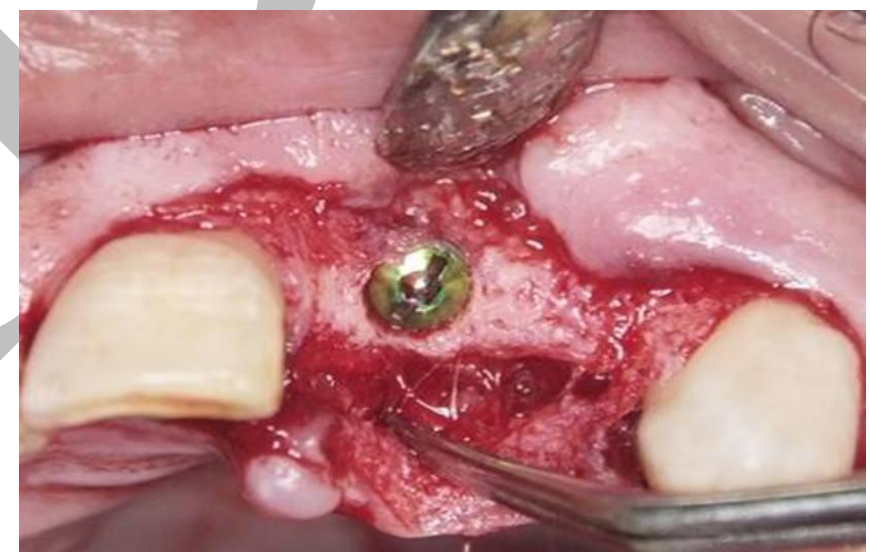

Fig. 2: Showing implant and cover screw in place (study group)

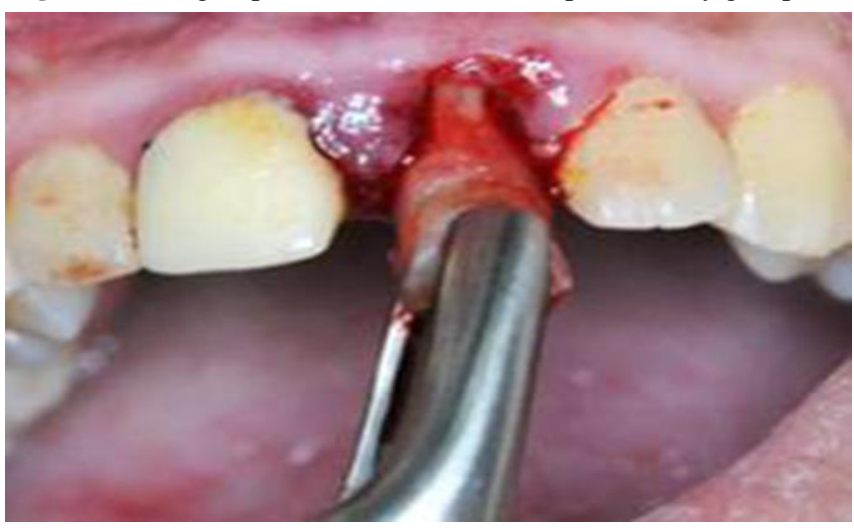

Fig. 3: Showing tooth extraction (control group) 
- Immediate implant was placed in position.

- Implant mount was removed and cover screw derived in place. (Figure 4)

- The easy graft material was prepared then packed in the socket around the implant at the coronal third.

- Suturing of the surgical site.

\section{Postsurgical phase}

- Postoperative instructions were given to the patients including cold packs on the first day, then warm mouth wash for the following days beside oral hygiene instructions. - Antibiotic Amoxicillin 500 mg (Emox 500 cap, Medical union pharmaceuticals, Abu-Sultan, Ismailia, Egypt) was prescribed for 5 days, 1 capsule every 8 hours.

- Non-steroidal anti-inflammatory drug Ibuprofen $400 \mathrm{mg}$ (Brufen 400 tab, Kahira pharma and Chem.ind.com, Cairo, Egypt) was prescribed for 3 days, 1 tablet every 8 hours.

- Chlorhexidine mouth wash (Hexitol MW, Arab drug company, Cairo, Egypt) for 7 days.

- Recall visit - the first week for suture removal.

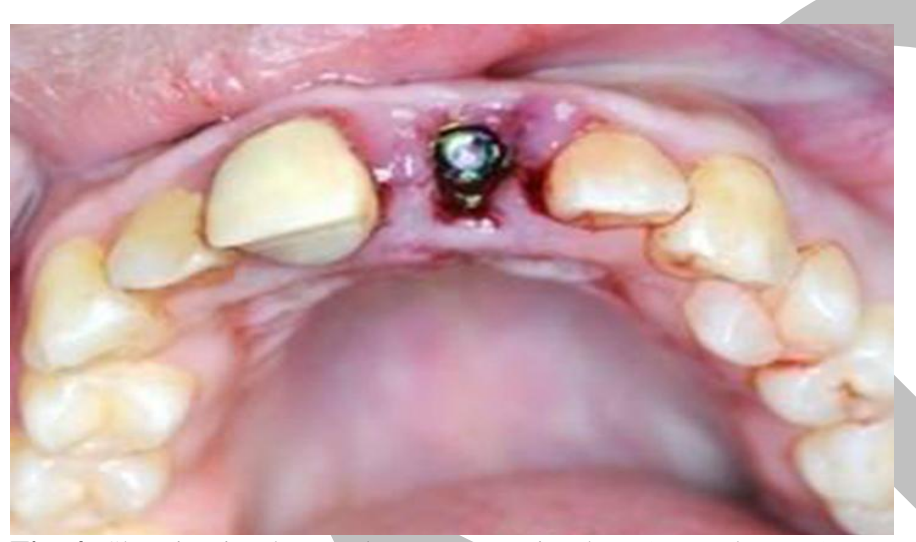

Fig. 4: Showing implant and cover screw in place (control group)

\section{Prosthetic phase}

Final restoration (porcelain fused to metal crown) was placed at 3 months following surgery

\section{Follow up phase}

\section{A- Clinical evaluation}

Each patient was clinically examined on intervals of 3 and 6 months. Patients were evaluated clinically for:

Mobility of the implant according to Mickney and Koth(12) Mobility was tested using back and forth pressure by two instrument handles. The clinical implant mobility scale is:

Absence of clinical mobility in any direction (Scale 0), slight detectable horizontal movement (Scale 1), moderate visible horizontal mobility up to $0.5 \mathrm{~mm}$ (Scale 2), severe horizontal movement greater than $0.5 \mathrm{~mm}$ (Scale 3) or visible moderate to severe horizontal movement and any visible vertical movement (Scale 4) .

Modified gingival index was used to assess the severity and quantity of gingival inflammation (13). Absence of inflammation (scale 0), mild inflammation or with slight changes in color and texture but not in all portions of marginal or papillary gingival unit (scale 1), mild inflammation, such as the preceding criteria, in all portions of gingival marginal or papillary gingival unit (scale 2), moderate, bright surface inflammation, erythema, edema and/or hypertrophy of marginal or papillary gingival unit (scale 3) or severe inflammation including erythema, edema and/or marginal gingival hypertrophy of the unit or spontaneous bleeding, papillary, congestion or ulceration (scale 4).

Peri-implant probing depth was done according to Clavind and Loe (1967) (14). After the final prosthesis was placed, peri-implant probing was done at the 3rd and 6th months as follow-up. Probing pocket depth refers to the distance from the gingival margin to the bottom of the pocket. Mesial and distal pockets were measured from the buccal aspect as close as possible to contact points while facial and lingual pockets were measured at the midline of the implant.

\section{B-Radiographic evaluation}

It was done immediately after implant placement, then at 3 and 6 months intervals post operatively. (Figures 5, 6)

Standardized periapical $\mathrm{X}$-ray films were taken using paralleling long cone technique by XCP film holder for standardization of serial radiographs, then indirect digital radiography by Image $\mathbf{J}$ software (15). These radiographic films were used to verify: bone density and marginal bone level around the implant.

Assessment of marginal bone height around the implants: mesial and distal bone height changes of the implants were evaluated using the linear measurement system supplied by the specially designed Image $\mathbf{J}$ software.

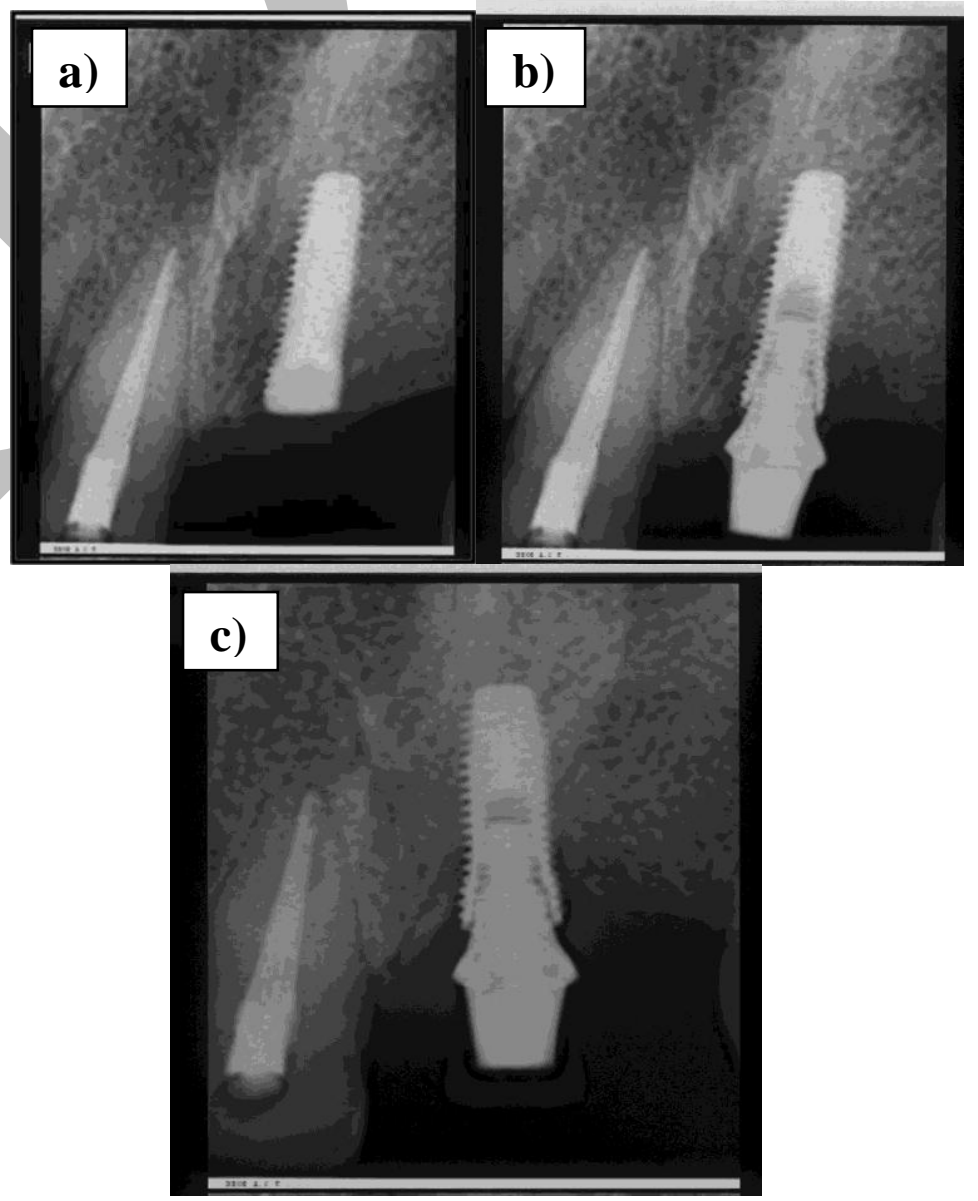

Fig. 5: Periapical $x$-ray for implants placed in study group; a) Immediate postoperative, b) After 3 months, c) After 6 months. 

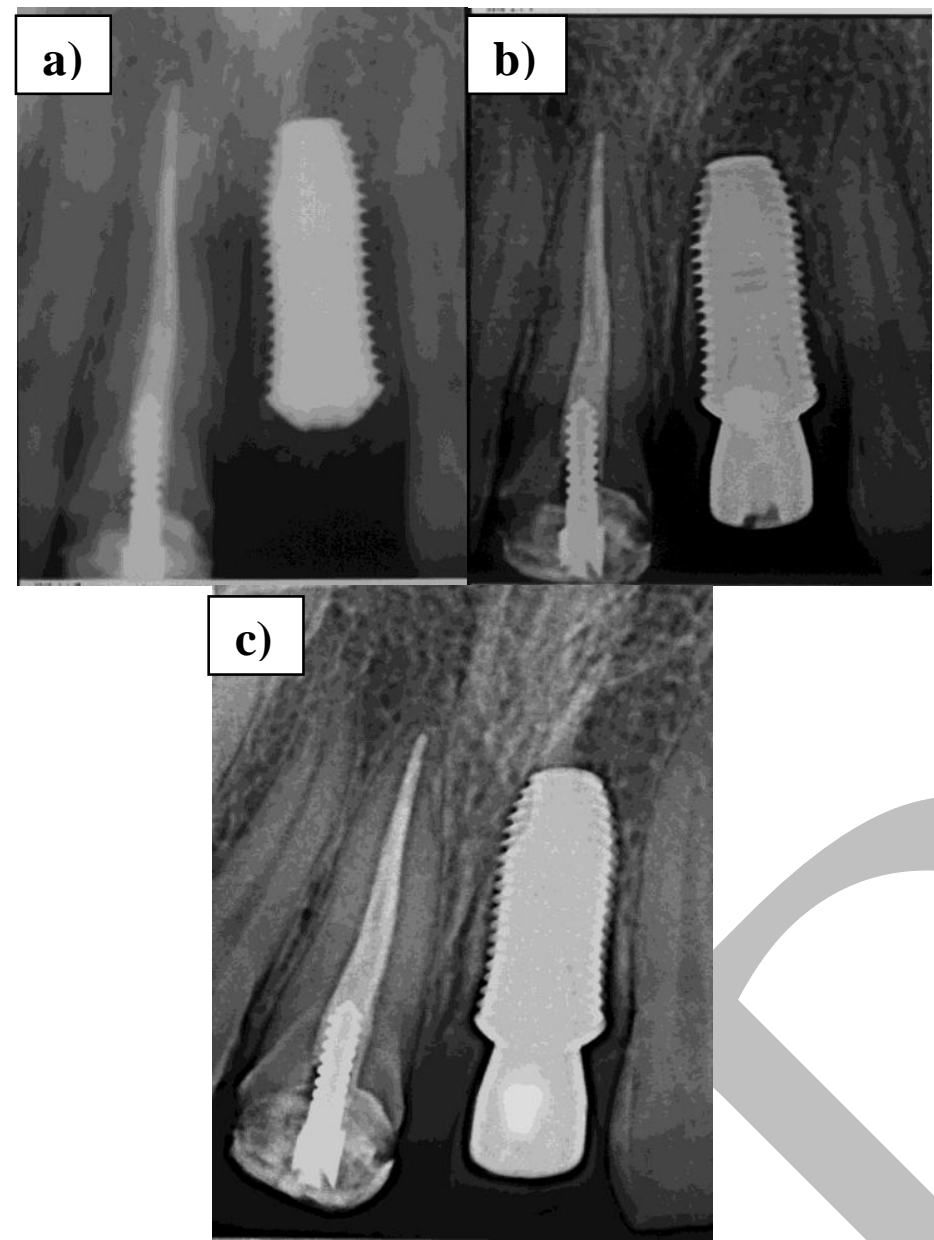

Fig. 6: Periapical $x$-ray for implants placed in control group; a) Immediate postoperative, b) After 3 months, c) After 6 months.

The distance from the top of the implant platform and the first point of bone-implant contact mesially and distally were used to represents the bone defect.

Measurement of the bone density around the implant: Image $\mathbf{J}$ software was used to evaluate radiographic bone density mesial and distal to each implant.

\section{Statistical analysis of the data}

Comparison between different groups regarding categorical variables was tested using Chi-square test. For normally distributed data, comparison between two independent populations was done using independent t-test, also paired ttest was used to analyze two paired data. Significance of the obtained results was judged at the $5 \%$ level.

\section{RESULTS}

\section{Clinical evaluation}

Implant Mobility was recorded all over the evaluation period, none of the implants showed any signs of mobility (i.e. mobility score was 0 ).

No signs of gingival inflammation were observed in all patients all over the evaluation period (i.e. modified gingival index score was 0).

Probing depth was measured for all the axial surfaces of all implants and statistical analysis of probing depth scores was done for all patients. Data collected were tabulated (table 1).
Table 1: Comparison between the two studied groups according to probing depth.

\begin{tabular}{|c|c|c|}
\hline \multirow{2}{*}{ Study } & \multicolumn{2}{|c|}{ Probing depth } \\
\cline { 2 - 3 } Min. - Max. & $\mathbf{3}^{\text {rd }}$ Month & $\mathbf{6}^{\text {th }}$ Month \\
Mean \pm SD. & $1.25-2.50$ & $0.75-2.0$ \\
Median & $1.82 \pm 0.51$ & $1.32 \pm 0.57$ \\
\hline $\mathbf{p}_{\mathbf{1}}$ & $0.002^{*}$ & .50 \\
\hline Control & & $<0.001^{*}$ \\
Min. - Max. & $1.70-2.75$ & $1.25-2.36$ \\
Mean \pm SD. & $2.30 \pm 0.35$ & $1.72 \pm 0.39$ \\
Median & 2.35 & 1.75 \\
\hline $\mathbf{p}_{\mathbf{1}}$ & $0.003^{*}$ & $0.001^{*}$ \\
\hline $\mathbf{t}$ & 2.024 & 1.509 \\
\hline $\mathbf{p}$ & 0.066 & 0.157 \\
\hline
\end{tabular}

$\mathrm{t}$ : Student t-test

p1: $\mathrm{p}$ value for Paired t-test for comparing between Immediate postoperative with each other periods in each group

*: Statistically significant at $\mathrm{p} \leq 0.05$

On the third month, the mean probing depth scores for the study group was $1.82 \pm 0.51$ while the mean probing depth scores for the control group was $2.30 \pm 0.35$. This difference in the probing depth score between the control and study group was found to be statistically not significant. $(\mathrm{p}=0.066)$.

On the sixth month, the mean probing depth scores for the study group was $1.32 \pm 0.57$ while the mean probing depth scores for the control group was $1.72 \pm 0.39$. This difference in the probing depth score between the control and study group was found to be statistically not significant. $(\mathrm{p}=0.157)$.

\section{Radiographic evaluation}

Data were collected regarding the marginal bone height at the mesial and distal aspects of all implants.

The mean marginal bone level values and standard deviation at 3 and 6 months of both groups were tabulated. (Table 2)

Table 2: Comparison between the two studied groups according to marginal bone height

\begin{tabular}{|c|c|c|}
\hline \multirow{2}{*}{ Study } & \multicolumn{2}{|c|}{ Marginal bone height } \\
\cline { 2 - 3 } Min. - Max. & $\mathbf{3}^{\text {rd }}$ Month & $\mathbf{6}^{\text {th }}$ Month \\
Mean \pm SD. & $0.15-0.37$ & \\
Median & $0.22 \pm 0.07$ & $0.20-0.57$ \\
\hline $\mathbf{p}_{\mathbf{1}}$ & 0.20 & $0.44 \pm 0.13$ \\
\hline Control & $<0.001^{*}$ & $<.50$ \\
Min. - Max. & $0.12-0.20$ & $0.001^{*}$ \\
Mean \pm SD. & $0.17 \pm 0.03$ & $0.30-0.50$ \\
Median & 0.18 & 0.30 \\
\hline $\mathbf{p}_{\mathbf{1}}$ & $<0.001^{*}$ & $<0.001^{*}$ \\
\hline $\mathbf{T}$ & 1.663 & 0.814 \\
\hline $\mathbf{P}$ & 0.122 & 0.431 \\
\hline
\end{tabular}

$\mathrm{t}$ : Student t-test

p1: $p$ value for Paired t-test for comparing between Immediate postoperative with each other periods in each group

*: Statistically significant at $\mathrm{p} \leq 0.05$ 
On the third month, the mean marginal bone level value for the study group was $0.22 \pm 0.07$ while the mean marginal bone level value for the control group was $0.17 \pm$ 0.03 . This difference in marginal bone level value between the study and control groups was not statistically significant. $(\mathrm{p}=0.122)$.

On the sixth month, the mean marginal bone level value for the study group was $0.44 \pm 0.13$ while the mean marginal bone level value for the control group was $0.44 \pm$ 0.13 . This difference in marginal bone level value between the study and control groups was no statistically significant. $(\mathrm{p}=0.431)$.

Mean peri-implant bone density values and standard deviation immediately post-operative, at 3 months and at 6 months were shown in (Table 3).

Table 3: Comparison between the two studied groups according to bone density

\begin{tabular}{|c|c|c|c|}
\hline & \multicolumn{3}{|c|}{ Bone density } \\
\hline & $\begin{array}{c}\text { Immediate } \\
\text { postoperative }\end{array}$ & $3^{\text {rd }}$ Month & $6^{\text {th }}$ Month \\
\hline \multicolumn{4}{|l|}{ Study } \\
\hline Min. - Max. & $85.10-101.51$ & $86.64-106.38$ & $90.33-107.02$ \\
\hline Mean \pm SD & $94.88 \pm 5.45$ & $96.74 \pm 6.12$ & $98.35 \pm 5.28$ \\
\hline Median & 97.20 & 98.23 & 99.25 \\
\hline $\mathbf{p}_{1}$ & & $0.014^{*}$ & $0.001^{*}$ \\
\hline \multicolumn{4}{|l|}{ Control } \\
\hline Min. - Max. & $81.48-91.94$ & $85.91-103.32$ & $93.22-105.0$ \\
\hline Mean \pm SD. & $93.88 \pm 3.96$ & $95.95 \pm 5.65$ & $98.80 \pm 3.58$ \\
\hline Median & 94.95 & 97.55 & 98.95 \\
\hline $\mathbf{p}_{1}$ & & $0.020^{*}$ & $0.003^{*}$ \\
\hline $\mathbf{T}$ & $2.747^{*}$ & 0.251 & 0.184 \\
\hline $\mathbf{P}$ & 0.701 & 0.806 & 0.857 \\
\hline
\end{tabular}

t: Student t-test

p1: $p$ value for Paired t-test for comparing between Immediate postoperative with each other periods in each group

*: Statistically significant at $\mathrm{p} \leq 0.05$

Immediately post-operatively, the mean peri-implant bone density value for the study group was $94.88 \pm 5.45$ while the mean peri-implant bone density value for the control group was $93.88 \pm 3.96$. This difference in the periimplant bone density value between the study and control groups was statistically not significant $(\mathrm{p}=0.701)$

On the third month, the mean peri-implant bone density value for the study group was $96.74 \pm 6.12$ while the mean peri-implant bone density value for the control group was $95.95 \pm 5.65$. This difference in peri-implant bone density value between the study and control groups was statistically not significant $(\mathrm{p}=0.806)$.

On the sixth month, the mean peri-implant bone density value for the study group was $98.35 \pm 5.28$ while the mean peri-implant bone density value for the control group was $98.80 \pm 3.58$. This difference in peri-implant bone density value between the study and control groups was statistically not significant $(\mathrm{p}=0.857)$.

\section{DISCUSSION}

The success of osseointegrated dental implants depends on whether there is a sufficient volume of healthy bone at the recipient site at the time of implant placement. The placement of an implant at a site with a thin crestal ridge (e.g., post extraction ridge) could result in a significant buccal dehiscence. Thus, it seems prudent to prevent alveolar ridge destruction and make efforts to preserve it during extraction procedures (16).

Alveolar ridge preservation is a surgical procedure aimed at retaining maximum bone and soft tissue after a tooth has been removed. By maintaining the original ridge morphology, there will be a minimal need for augmentation procedures thereby allowing the resultant restoration to be placed in an aesthetically and functionally ideal position (17).

Simion et al (18) reported that success rates are satisfactory when placing implants in previously grafted bone. In a restrospective study of 607 titanium plasma sprayed implants placed in regenerated bone (with DFDBA), $97.2 \%$ of maxilla implants and $97.4 \%$ of mandible implants were successful for an average of 11 years.

This study was designed to assess whether it could be advantageous to place implants immediately after tooth extraction or if it would be preferable to preserve the socket, wait for bone healing and then place the implant.

Seven implants were placed after 6 months of socket preservation (study group) while the other implants were placed immediately after teeth extraction (control group).

As regarding patient selection, all patients were free from any systemic diseases such as diabetes mellitus, renal and endocrinal disturbances, blood dyscrasias and osteoporosis. All patients in the current study were nonsmokers. Nicotine, which is the major component of tobacco, is cytotoxic and prevents differentiation of osteoblasts like cells to osteoblasts thus reducing alveolar bone quality (19).

Regarding the surgical procedure, all included patients were subjected to delicate surgery using delayed implant placement protocol for the study group and immediate placement protocol for the control group. In the study group a crestal incision and elevation of full thickness mucoperiosteal flap was performed to provide adequate access. In the control group atraumatic extraction technique used to preserve the buccal plate of bone. In both groups a low speed high torque hand piece was used for the preparation of the implant bed, and the drilling was performed under profuse irrigation using cold normal saline for proper cooling and to avoid overheating of the bone tissues which would compromise osseointegration in accordance to Strbac et al (20). This also matches findings obtained by Lee et al (21), and Augustin et al (22).

In the present study, a two - stage implantation procedure was selected to allow for prolonged direct boneimplant interface and unimpeded healing of the augmented ridge before implant exposure to functional load (23). 
In this study we used easy graft material (pure beta tricalcium phosphate) as a bone graft substitute which was prepared by mixing the granules with biolinker then was packed around the implant in the coronal gap between the fixture and the socket wall. This agreed with Ormianer et al (2006) (24). They assessed the survival of 1065 immediately placed dental implants in augmented alveolar bone sites in 338 patients. Beta tricalcium phosphate was used to augment the alveolar ridge level, fill spaces between the implant and socket wall. 97.6\% of the implants survived during the observation period of 12 to 48 months.

In the present study, wound closure was performed very carefully using $3 / 0$ black silk suture material in order to prevent postoperative infection and inflammation, epithelial down growth and bone loss of the alveolar crest during the healing period as recommended by Becker and Becker in 1990 (25).

Postoperative medications including antibiotics, mouth washes, analgesics and anti-inflammatory drugs were prescribed to all patients. Oral hygiene instructions were given to all patients early in their treatment and reinforced during the subsequent appointments so as to decrease the possibility of plaque accumulation and inflammation around the implants. This enhances the success rate of implant osseointegration and prosthetic rehabilitation (26).

Regarding implant mobility, no clinical mobility was detected in any of the implants throughout the follow up period. This was confirmed by radiographic evaluation that revealed intimate bone implant contact and absence of periimplant radiolucency.

All cases showed a modified gingival score of 0 throughout the evaluation period indicating absence of periimplant mucositis, which is a criteria of implant success as peri-implant mucositis may lead to progressive bone destruction (peri-implantitis) and ultimately to implant failure as reported by Esposito et al (27).

Regarding the mean peri-implant probing depth in the present study there was a decrease throughout the whole evaluation period for both groups. Similar results were reported by Al-Ansari and Morris (28).

Regarding to peri-implant bone level, there was no statistically significant difference between two groups all over the evaluation period. This could be attributed to the effect of the easy graft material as an osteoconductive bone graft.

Both groups showed increase in peri-implant bone density from the immediate postoperative period to the end of the 6 months of the evaluation period, which indicates osseointegration of all implants.

\section{CONCLUSIONS}

Within the limits of this study the overall conclusion that can be drawn from this study is that there is no significant difference in marginal bone level and bone denisty around implants placed after socket preservation compared to those placed immediately after tooth extraction.

It is apparent from this study that maintenance of an extraction socket for future implant therapy does not exclude immediate implant placement, but knowledge and experience are needed to determine the best treatment modality.

\section{STATEMENT OF CONFLICT OF INTEREST}

The authors declare that they have no conflicts of interest.

\section{REFERENCES}

1. Lekovic V, Camargo PM, Klokkevold PR, Weinlaender M, Kenney EB, Dimitrijevic B, et al. Preservation of alveolar bone in extraction sockets using bioabsorbable membranes. J Periodontol. 1998; 69: 1044-9.

2. Schropp L, Wenzel A, Kostopoulos L, Karring T. Bone healing and soft-tissue contour changes following single-tooth extraction: a clinical and radiographic 12month prospective study. Int J Periodontics Restorative Dent. 2003; 23: 313-23.

3. Barone A, Aldini NN, Fini M, Giardino R, Calvo Guirado JL, Covani U. Xenograft versus extraction alone for ridge preservation after tooth removal: a clinical and histomorphometric study. J Periodontal. 2008; 79: 1370-7.

4. Zitzmann NU, Scharer P, Marinello CP, Schupbach P, Berglundh T. Alveolar ridge augmentation with BioOss: a histologic study in humans. Int J Periodontics Restorative Dent. 2001; 21: 288-95.

5. Becker W, Clokie C, Sennerby L, Urist MR, Becker BE. Histologic findings after implantation and evaluation of different grafting materials and titanium micro screws into extraction sockets: case reports. J Periodontol. 1998; 69: 414-21.

6. Camargo PM, Lekovic V, Weinlaender M, Klokkevold PR, Kenney EB, Dimitrijevic B et al. Influence of bioactive glass on changes in alveolar process dimensions after exodontia. Oral Surg Oral Med Oral Pathol Oral Radiol Endod. 2000; 90: 581-6.

7. Artzi Z, Tal H, Dayan D. Porous bovine bone mineral in healing of human extraction sockets: 2. Histochemical observations at 9 months. J Periodontol. 2001; 72: 152-9.

8. Froum S, Orlowski W. Ridge preservation utilizing an alloplasts prior to implant placement - clinical and histological case reports. Pract Periodontics Aesthet Dent. 2000; 12: 393-402.

9. Iasella JM, Greenwell H, Miller RL, Hill M, Drisko C, Bohra AA, et al. Ridge preservation with freeze-dried bone allograft and a collagen membrane compared to extraction alone for implant site development: a clinical and histologic study in humans. J Periodontol. 2003; 74: 990-9.

10. Bauer TW, Muschler GF. Bon graft materials:An overview of the basic Science. Clin Orthop Relat Res. 2003; 371: 10-27.

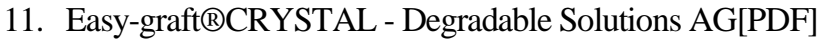

12. Steflik D, Koth DL, Robinson F, Mckinney R, Davis B, Morris $\mathrm{C}$, et al. prospective investigation of the singlecrystal sapphire endosteal dental implant in humans: Ten-year results. J Oral Implantol. 1995; 21: 8-18.

13. Lobene RR, Weatherford T, Ross NM, Lamm RA, Menaker L. A modified gingival index for use in clinical trials. Clinical Preventive Dentistry. 1986;8:3-6.

14. Glavind L, Loe H. Errors in clinical assessment of periodontal destruction. J Periodontol. 1967;2: 180-6. 
15. Abramoff MD, Magelhase PJ, Ram SJ. Image processing with image J. Biophonetics Interational. 2004; 11: 36-42.

16. Tassos Irinakis. rational for socket preservation after extraction of single rooted tooth when planning for future implant placement. J Can Dent Assoc. 2006; 72: 917-22.

17. Darby I, Chen ST, Buser D. Ridge preservation techniques for implant therapy. Int J Oral Maxillofac Implants. 2009; 24:260-71.

18. Simion M, Jovanovic SA, Tinti C, Benfenati SP. Longterm evaluation of osseointegrated implants inserted at the time or after vertical ridge augmentation. A retrospective study on 123 implants with 1-5 year follow-up. Clin Oral Implants Res. 2001; 12: 35-45.

19. Nociti F, Cesar N, Carvalho M, Sallum E. Bone denisty around titanium implants may be influenced by intermittent cigarette smoke inhalation: A histometric study in rats. Int J Oral Maxillofac Implants. 2002; 17: 347-52

20. Strbac GD, Unger E, Donner R, Bijak M, Watzek G, Zechner W. Thermal effects of acombined irrigation method during implant site drilling. A standdized in vitro study using a bovin rib model. Clin Oral Implants Res. 2014; 25: 665-74.

21. Lee J, Ozdoganlar OB, Rabin Y. An exprimental investigation on thermal exposure during bone drilling. Med Eng Phys. 2012; 34: 1510-20.

22. Augustin G, Davila S, Udillijak T, Staroveski T, Brezak D, Babic S. Temperature changes during cortical bone drilling with a newly designed step drill and an internally cooled drill. Int Orthop. 2012; 36: 1449-56.

23. Zoghbi SA, De lima LA, Saraiva L, Romito GA. Surgical experience influences two stages implant osseointegration. J Oral Maxillofac Surg. 2011;69: 2771-6.

24. Ormianer Z, Palti A, Thoma K, Pajarola GF, Kan W, Shifman A. Servival of immediately placed dental implants in deficient alveolar bone sites augmented with beta-tricalcium phosphate. Implant Dent. 2006;15:395403

25. Porter J, Von Fraunhofer J, Success or failure of dental implants?A literature review with treatment considerations. General Dent. 2005; 423-32.

26. Hossein K, Dahlin C, Bengt A. Influence of different prophylactic antibiotic regimens on implant survival rate: Aretrospective clinical study. Clin Oral Impl Dent Relat Res. 2005; 7: 32-5.

27. Esposito M, Grusovin MG, Tzanetea E, Piattelli A, Worthington $\mathrm{H} \mathrm{V}$. Interventions for replacing missing teeth: treatment of perimplantitis. Cochrane Database Syst Rev. 2010; 6: CD004970.

28. Al-Ansari, Bader H, Robert R. Morris. "Placement of dental implants without flap surgery: a clinical report. Int J Oral Maxillofac Implants. 1998; 13: 861-5. 